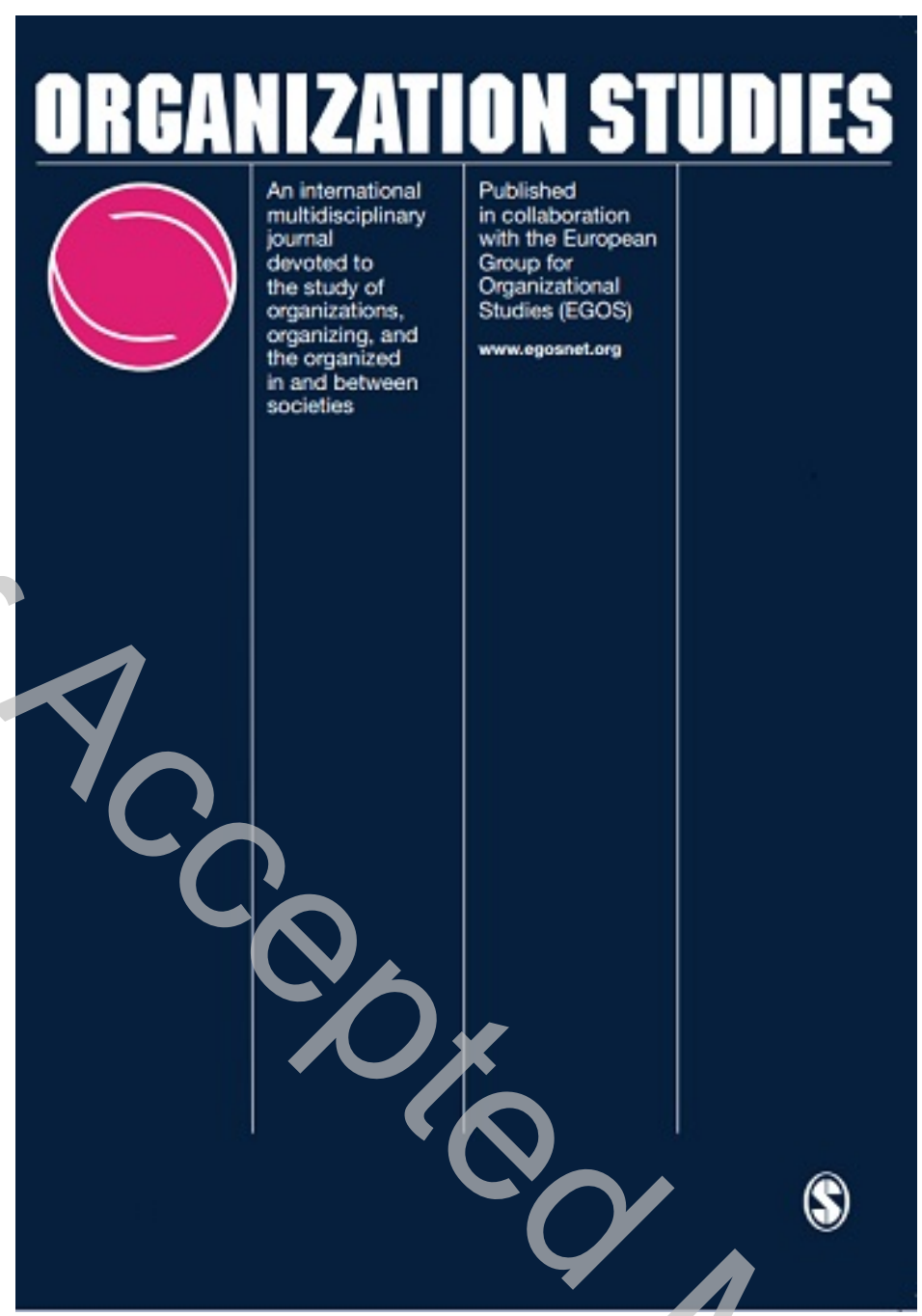

\title{
Space and sensemaking in high-reliability task contexts: Insights from a maritime mass rescue exercise
}

\begin{tabular}{|r|l|}
\hline Journal: & Organization Studies \\
\hline Manuscript ID & OS-19-0568.R6 \\
\hline Kanuscript Type: & Article \\
\hline Abstract: & $\begin{array}{l}\text { Sensemaking theory < Theoretical Perspectives, Ethnography } \\
\text { Research Design and Data Collection, Non-profit organizations, civil } \\
\text { society < Topics }\end{array}$ \\
\hline & $\begin{array}{l}\text { The spatial environment shapes sensemaking in complex situations. } \\
\text { While we know that actors in high-reliability task contexts often have a } \\
\text { unclear how they entrol over their spatial environment, it remains } \\
\text { has on their sensemaking. In this paper, we use micro-ethnographic this } \\
\text { video data from two maritime mass rescue exercises to fill this gap. We }\end{array}$ \\
\hline
\end{tabular}




\section{SCHOLARONE ${ }^{\text {M }}$} Manuscripts

find that actors that are under a high cognitive load enact space incidentally and fail to re-enact their spatial environment when problems arise. Instead, actors engage in micro-activities that temporarily mitigate the problems created by their space enactment. We develop a model on space and sensemaking in high-reliability task contexts that distinguishes between unenacted, enacted and lived space. Our findings point towards nested sensemaking, where the enacted spatial environment becomes part of the overall 'story' of an operation. Our findings have implications for our understanding of space and sensemaking in high-reliability task contexts, provide opportunities to improve high-reliability organizations' performance and add to research on space and organising.

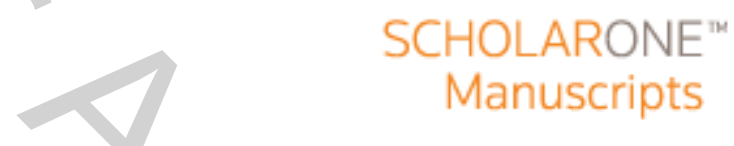




\title{
Space and sensemaking in high-reliability task contexts:
}

\section{Insights from a maritime mass rescue exercise}

\author{
Norbert Steigenberger \\ Jönköping International Business School, Jönköping University, Sweden
}

Thomas Lübcke

German Maritime Search and Rescue Service - DGzRS, Germany

\begin{abstract}
The spatial environment shapes sensemaking in complex situations. While we know that actors in high-reliability task contexts often have a certain degree of control over their spatial environment, it remains unclear how they enact their spatial environment and which effect this has on their sensemaking. In this paper, we use micro-ethnographic video data from two maritime mass rescue exercises to fill this gap. We find that actors that are under a high cognitive load enact space incidentally and fail to re-enact their spatial environment when problems arise. Instead, actors engage in micro-activities that temporarily mitigate the problems created by their space enactment. We develop a model on space and sensemaking in high-reliability task contexts that distinguishes between unenacted, enacted and lived space. Our findings point towards nested sensemaking, where the enacted spatial environment becomes part of the overall 'story' of an operation. Our findings have implications for our understanding of space and sensemaking in high-reliability task contexts, provide opportunities to improve high-reliability organizations' performance and add to research on space and organising.
\end{abstract}

\section{Keywords}

sensemaking, space, spatiality, high-reliability organisations, micro-ethnography, videoethnography

Corresponding author: Norbert Steigenberger, Jönköping International Business School, Gjuterigatan 5, 55318 Jönköping, Sweden. Email: norbert.steigenberger@ju.se 
Sensemaking - the process of transferring complex realities into simplified representations that allow purposeful action (Maitlis \& Christianson, 2014; Weick, 1988) - is central in high-reliability task contexts when actors need a strong understanding of situations for which routines and standard procedures do not suffice (Cornelissen, Mantere \& Vaara, 2014; Faraj \& Xiao, 2006). Actors' ability to effectively make sense of complex situations - their ability to perceive cues, process cues and act on the resulting mental models (Maitlis, 2005)-is often affected by their spatial environment, which determines what actors can see or hear and whom they can reach out to (Cornelissen et al., 2014; Schakel, van Fenema \& Faraj, 2016; Weick, 1993).

Previous research on sensemaking in high-reliability task contexts treated space largely as a 'container', as something static and defined by fixed boundaries (Stephenson, Kuismin, Putnam \& Sivunen, 2020). We learned, for example, that the spatial environment played an important role in the Stockwell shooting in London in 2005, as physical objects obstructed the view of police officers, which led to fatal sensemaking errors (Cornelissen et al., 2014), or that the pilot-not-flying sitting in the captain's seat complicated collective cue processing and actions during the ill-fated Air France 447 flight in 2009 (Oliver, Calvard \& Potočnik, 2017). The container perspective is important, yet incomplete; it neglects that actors often have a certain degree of control over their spatial environment. To comprehend how space and sensemaking relate, we need to expand our current understanding and theorise space as a product of action instead of a condition external to the actor, consistent with broader organisation theory, which understands space as a constructed and constitutive element of organising (Beyes \& Holt, 2020; Ratner, 2020).

To build our understanding of how actors in high-reliability task contexts enact their spatial environment, we studied two large maritime mass rescue exercises, where actors had to make sense of complex information to be able to act successfully. Employing micro-ethnographic video data we found that actors importantly shaped their spatial environment but exhibited very little control over how they did so. Once they had enacted their spatial environment, they engaged in microactivities that temporarily altered but did not substantially improve the spatial environment they had created, even as the enacted spatial environment proved to be problematic. Our findings allow 
us to derive why this was the case and develop a model in which we differentiate among unenacted, enacted and lived space, where lived space is the continuously recreated product of a recursive process between sensemaking and space-mitigating microactivities. We further theorise that these findings are indicative of nested sensemaking, wherein the enacted space becomes part of the 'story' of an operation that is not challenged, even when shown to be counterproductive.

Our study advances research on sensemaking in high-reliability task contexts by developing theory on how actors enact their spatial environment (Christianson, 2019; de Rond, Holeman \& HowardGrenville, 2019; Introna, 2019). We also contribute to the ongoing effort to comprehend how space and organising interrelate (Cnossen \& Bencherki, 2019; Gonsalves, 2020; Lee, 2019; Ratner, 2020) by introducing cognitive load as an important factor. Finally, we provide guidance for practitioners in high-reliability organisations, outlining how the purposeful enactment of space could improve actors' performance in complex situations.

\section{Sensemaking in High-Reliability Task Contexts}

Sensemaking is 'a process prompted by violated expectations that involves attending to and bracketing cues in the environment, creating intersubjective meaning through cycles of interpretation and action, and thereby enacting a more ordered environment from which further cues can be drawn' (Maitlis \& Christianson, 2014, p. 67). Sensemaking has three steps: cue perception, cue processing and action. A sensemaker may go through several iterations of perceiving, processing and acting until a stable mental model emerges, which the sensemaker then retains until new information challenges this model. If that happens, the sensemaker either updates the mental model (Christianson, 2019) or engages in new sensemaking to replace it (Maitlis, 2005). Such mental models are depictions of a situation that are "consensually valid, experience-based and informed by activity that clarifies puzzling cognitions' (Weick, 2010, pp. 540-541).

Sensemaking is central in high-reliability task contexts (Dwyer, Hardy \& Maguire, 2021; Weick, 1988; Weick, Sutcliffe \& Obstfeld, 2005). Medical teams make sense of symptoms and patient conditions (Faraj \& Xiao, 2006), police units attempt to understand the behaviour of suspects (Schakel et al., 2016), and cockpit crews interpret critical events during flights (Oliver et al., 2017). 
Sensemaking and action are intertwined; sensemakers act according to how they understand a specific situation, and the cues their actions produce are incorporated into their sensemaking (Christianson, 2019; Maitlis \& Christianson, 2014). In high-reliability task contexts, the relation between cue perception, cue processing and action has been described as following a 'logic of tact' (Kornberger, Leixnering \& Meyer, 2019), where actions are based on iterative and incomplete mental models of a situation.

Sensemaking can be individual or involve interactions between sensemakers. Individual sensemaking is a largely automatic and preconscious process (Schildt, Mantere \& Cornelissen, 2020). Interpretations of the same objective reality typically differ between sensemakers, as each interprets reality from their own perspective (Gary \& Wood, 2011). Collective sensemaking is therefore often required to coordinate activities (Faraj \& Xiao, 2006), which can happen based on a shared understanding of roles, routines and responsibilities ('heedful interrelations', (Weick \& Roberts, 1993)), via 'action patterning' (Danner-Schröder \& Geiger, 2016) or via dialogue in situations where heedful interrelations and pattern-based coordination are hampered by many cues, ambiguous cues or unfamiliarity with a situation (Faraj \& Xiao, 2006). Dialogues allow for the conscious integration of different perceptions and perspectives into a collective mental model. For example, engineers might discuss why a control system readout is or is not problematic (Dunbar \& Garud, 2009), and doctors and nurses might deliberate about surprising occurrences during surgery (Faraj \& Xiao, 2006).

\section{Sensemaking and Space}

Sensemaking processes are shaped by the spatial environment in which they are situated (Halford \& Leonard, 2006; Introna, 2019), resonating with the literature on coordination in organisations, which reports that space constrains and enables organisational practices and produces or alters meaning (Cnossen \& Bencherki, 2019; Giovannoni \& Quattrone, 2018; Sivunen \& Putnam, 2019). Space describes the physical properties of a material environment, such as the distance between persons, objects and physical artefacts; their spatial relationships; and the physical boundaries that constrain sight and encourage movement (Taylor \& Spicer, 2007; Weinfurtner \& Seidl, 2019). 
Space can also imply boundaries that demarcate social relations or identities (Weinfurtner \& Seidl, 2019).

Previous research has studied how the spatial environment affects cue perception, cue processing and action in high-reliability task contexts. First, space influences the cues that actors perceive. In high-reliability task contexts, information is often spatial in nature. Schakel et al. (2016) and Cornelissen et al. (2014), for example, explain how cues are lost to police when they appear outside the police officers' line of sight. Beane and Orlikowski (2015) reported that being virtually at a patient's bedside by videoconferencing can improve cue acquisition by residents not physically present in a hospital.

Second, space influences the interpretation and discussion of cues. Weick (1993), for example, reported how spatial distance between firefighters caused breakdowns in coordination and communication. Oliver et al. (2017) studied the ill-fated 2009 AF flight 447 and discussed how a copilot in the pilot chair impeded the crew's ability to collectively process cues. de Rond et al. (2019) explained how being at a specific place (in a rowing boat on the Amazon River) led to important 'from the body' experiences that shaped the rowing crew's interpretation of cues.

Finally, space influences action and whether and how the cues produced by actions re-enter the sensemaking process. The spatial placement of instruments, doors and workplaces on large vessels, for example, affects the ways in which navigation teams plot courses and distribute work (Hutchins, 1995). Sergeeva, Faraj and Huysman (2020) reported how the presence of surgical robots changes the coordinated action of surgical teams, as the robot, which takes up space around the patient, disconnects the surgeon from the resident in training, excluding the resident in training from ongoing action.

Previous research thus provides ample evidence that space has a strong effect on how sensemaking unfolds in high-reliability task contexts as it pertains to cue perception, cue processing and action. However, we currently understand space in sensemaking predominantly as a static property of the physical environment. Yet space is not something sensemakers passively endure. In contrast, space 
is 'enacted,' resulting from the interplay among its physical properties and the actions and perceptions of individuals (Sivunen \& Putnam, 2019).

The notion that space is enacted has gained traction in the organisational coordination literature (Cnossen \& Bencherki, 2019; Giovannoni \& Quattrone, 2018; Mengis, Nicolini \& Gorli, 2018; Sivunen \& Putnam, 2019) but is not well represented in our understanding of space and sensemaking. This has created a disconnect between sensemaking research and recent research on space and organising, which might lead researchers to ask incomplete questions. Rather than investigating how space leads sensemakers to overlook cues, we might more profitably ask why sensemakers enact their spatial environments in ways that render space an obstacle to cue perception and try to understand how they navigate the tensions created by their enacted spatial environment.

In this study, we forward this enactment perspective to enable a better understanding of space in the sensemaking of actors in high-reliability task contexts. We ask how actors enact space in relation to the three stages of the sensemaking process: cue perception, cue processing and action, focusing on situations that impose a high cognitive load on the actors. We study how sensemaking and the enactment of space influence each other, which helps us understand the interdependence of space and sensemaking in high-reliability task contexts.

\section{Case and Research Methods}

\section{Research Setting}

Our study is based on fieldwork in maritime search and rescue (SAR). Maritime SAR covers emergency response operations related to maritime incidents, such as searches for missing persons and vessels, medical aid, firefighting and technical assistance at sea. Maritime SAR is a highreliability task context in which decisions often have consequences that affect life, health or the environment (O'Neil \& Kriz, 2013). These contexts have been at the centre of much research interest and have been singled out as a particularly promising field to develop organisation theory (Hällgren, Rouleau \& de Rond, 2018). 
We study two large-scale mass rescue exercises conducted in 2014 and 2015. Mass rescue operations are responses to incidents that pose an immediate and often life-threatening danger for many people. These are rare incidents, but when they occur, they are extraordinarily challenging and impactful (so-called low-probability high-impact events) (Weick, 1988). This vicious combination is a challenge for SAR agencies, particularly as the complexity of these events prevents standardisation of tactical and operational approaches and realistic exercises are central to deyeloping relevant competences and capabilities (Steigenberger, 2016). Such exercises are expensive high-profile events for which hundreds of personnel and a significant number of vessels and airborne units must be gathered, complex training scenarios must be designed and volunteers and target ships must be provided. In 2014 and 2015, the Royal Danish Navy hosted international mass rescue exercises in the Baltic Sea region offshore from the Island of Bornholm, which operated under the name Baltic SAREX. Dozens of vessels, several helicopters and some hundred personnel participated in these week-long exercises. The substantial commitment of resources, the social pressure created by meeting colleagues from numerous vessels, professions and countries, and the omnipresence of 'umpires,' who would note and discuss the performance of the participants in semi-public debriefings, ensured that participants took the exercises very seriously.

An open-water mass rescue operation was the climax of Baltic SAREX 2014 and 2015-a passenger ferry had collided with a cargo ship. Both vessels required firefighting and technical assistance as they were taking on water, and injured passengers on the ferry had to be brought to safety. All of this happened several miles from shore and with vessels that normally perform their line duties in this sea region.

We were interested in a section of the operation that closely follows our theoretical interest: control of operations on the bridge of the distressed vessel. According to the guidelines of the Royal Danish Navy, which complies with the standards issued by the International Maritime Organisation (IMO), mass rescue operations are managed on site by an on-scene coordinator who oversees the operation from his or her ship. The on-scene coordinator appoints subcoordinators as needed, one of which is the local incident coordinator (LICO) who is sent to the distressed vessel to act as a liaison 
between the on-scene coordinator and the master of the distressed vessel, collecting information and supporting the master in coordinating the activities on board (Møller, 2014). Although this hierarchical structure is standardised, the LICO has substantial decision-making agency, as the situation on board a distressed vessel is beyond standardisation.

The LICOs brought two persons to support them: a LICO assistant and a tallyman. In both years, the LICO teams were officers in the Royal Danish Navy. As all were male, we used the following male pronouns. Most of the passengers on board the distressed vessels were Danish volunteers, and the crews of the vessels were regular crews. Several umpires, one of whom is the second author of this paper, were on board. Both exercises ran for approximately 4.5 hours, from the mayday call to the 'end of exercise' order.

\section{Method and Data}

Consistent with previous sensemaking research (Christianson 2019; Liu \& Maitlis 2014) and recent methodological recommendations for studies on sensemaking and materiality (Christianson, 2018; Mengis et al., 2018), we employ a microethnographic approach that utilises video data to study moment-to-moment interactions. Video data are well suited to study how actors relate to each other and their environment (LeBaron, Jarzabkowski, Pratt \& Fetzer, 2018), and these data have been used frequently in recent years (Christianson, 2018). Based on the notion that sensemaking is episodic (Sandberg \& Tsoukas, 2015), we apply a case-within-case design, comparing sensemaking episodes within and between operations as well as the dynamics within sensemaking episodes. This enables us to work with subcases that differ in terms of their spatial environment but are comparable in other dimensions, such as organisational background, which allows for crossand within-case analyses (Eisenhardt, 1989). We complement our video data with participant observations, interviews and secondary data.

In both the 2014 and 2015 Baltic SAREX mass rescue operations, we recorded the LICOs' activities with video cameras. After the exercises, a professional film-editing service aligned the video footage to obtain time-synchronized split-screen videos, and a professional translating service translated the Danish portion of the verbal communications into English. The camera setup 
combined a panoramic view (an objective angle from a top-down perspective with a static camera) with an infrasubjective view (a subjective angle via body cameras). This setup facilitated a comprehensive understanding of the emerging relationships and minimised biases induced by camera angles and camera movements (Mengis et al., 2018). Each camera had its own audio channel, which provided several audio streams for the analysis.

To complement the video data, we used a variety of other data sources. As a precursor to this study, we completed introductory training in maritime SAR techniques and spent several days aboard SAR vessels to gain an in-depth understanding of the field. The second author was one of the planning staff for Baltic SAREX 2014 and 2015, which provided us with free access to the exercise, exercise orders and planning documents. To refine our understanding of which aspects of the LICOs' actions were based on codified work processes, we read the guidelines of both the IMO and the Royal Danish Navy for large-scale mass rescue operations. Prior to Baltic SAREX 2014, we interviewed maritime SAR professionals to become familiar with the inherent challenges of this field (Hoffman, Crandall \& Shadbolt, 1998). After Baltic SAREX 2014, we interviewed two high-ranking field experts from the Royal Danish Navy. These interviews proved to be critical for identifying sensemaking episodes, helping us ensure the field validity of our interpretations and providing input for coding. During and after Baltic SAREX 2014 and 2015, we conducted informal interviews with participants during coffee breaks and at debriefings and social events to learn their perspectives and opinions. Table 1 presents our data, and Figure 1 shows examples of the splitscreen video data.

Table 1 and Figure 1

\section{Data analysis}

Our analysis involved four steps: sequencing, coding the spatial environment, identifying the enactment of space and building a theoretical framework. 
Step 1. Sequencing. The first step was to identify sensemaking episodes and establish the start and end points of each episode (Gylfe, Franck, LeBaron \& Mantere, 2016). We first watched the videos to identify instances in which the LICOs faced a sensemaking trigger: 'events, issues and actions that [are] somehow surprising or confusing' (Maitlis, 2005, p. 21). Then, we studied the exercise documents and the IMO and Danish Navy guidelines to ensure that these instances were not covered by standard operating procedures. In addition, we watched the video footage of Baltic SAREX 2014 in the company of two high-ranking field experts from the Danish Royal Navy. During this session, which lasted approximately eight hours, we discussed the details of each step in the operation, the decisions that the LICOs had to make and the challenges they faced. We then cross-checked the interviewees' statements against our list of sensemaking episodes. In the next step, we distinguished new sensemaking episodes from updates, with reference to Christianson (2019). We classified situations as updates when new information related to an ongoing sensemaking episode became available. This procedure resulted in a final list of 21 distinct sensemaking episodes, 11 in Baltic SAREX 2014 and 10 in Baltic SAREX 15, as outlined in Table 3.

For each episode, we captured its length, its content, the information sources used by the sensemaker(s), whether the episodes involved discussions, who the discussants were and who was present at the scene but did not participate in discussions (Gylfe et al., 2016).

Step 2. Coding the spatial environment. Drawing on Weinfurtner and Seidi (2019), we then coded boundaries (physical and social), movement (a change of position in space) and distances between (potential) sensemakers and between sensemakers, objects and occurrences in these sensemaking episodes. Physical boundaries and distances determined the sensemakers' ability to perceive cues and the ways in which individuals could relate to each other. Social boundaries pertain to body posture and visual gaze, which either encourage or discourage communication. ${ }^{1}$

Step 3. Identifying the enactment of space. We then cross-referenced space and sensemaking episodes to understand how the space was enacted. Following Gylfe et al. (2016) and prior studies that have developed theory based on video observations (Christianson, 2019; Liu \& Maitlis, 2014), 
we examined the material and bodily expressions and interactions of actors in detail to understand the interface between sensemaking and space, the interactions with artefacts, visual gaze, the focus of attention, movements and dialogues. We then made cross-case and within-case comparisons to deepen our understanding of how spatial properties or activities that relate to space affected sensemaking and how the sensemakers affected their boundaries and distances and thus their spatial environment. We incorporated field observations and insights from the formal and informal interviews to complete the picture.

Step 4. Building a theoretical framework. We then went back and forth between the data and theory to refine our understanding of the findings. In line with comparable research on the role of space in organisations (Gonsalves, 2020), we adopted an abductive approach, starting from established knowledge regarding the role of space in organisational processes and established sensemaking research (Mantere \& Ketokivi, 2013).

\section{The operation and the vessels}

Table 2 presents an overview of the operations. In stage 1, the LICO team entered the distressed vessel through a pilot door on a lower deck (see Figure 2). There was a fire on the ship, the ship was taking on water, and injured persons were scattered in various locations on the vessel. The LICO had to reach the bridge and set up a work area. In stage 2, he had to establish an overview of the situation, and request, commit and coordinate resources. Another important task was to establish a reliable headcount. In stage 3, the LICO oversaw operations until the vessel had been evacuated and declared technically safe.

\section{Table 2}

Figure 2 shows the distressed ships. The circles in both photographs mark the pilot doors through which the LICO teams and resources (e.g., firefighters, pump capacities) entered the ships. The bridges are located behind the large windows at the top of the vessels. The LICOs were familiar 
with these types of vessels but had not worked on them previously. On the bridge, they had access to the vessel safety plans, which contain a detailed depiction of the vessel's layout, including predetermined evacuation points.

Figure 2

Figure 3 shows schematics of the bridges of the two vessels, depicting typical situations after the LICOs had set up their workplaces. In the figure, the LICOs (pink shirts) and the crewmembers who participated in the operations (white shirts) are at their stations. Figure 4 shows these situations in the videos.

\section{Figure 3 and 4}

\section{Findings}

Table 3

\section{Enactment of space and cue perception}

The effect of space on cue perception was determined by the location of the actors, which was consequence of the initial decision made by both LICOs after arriving on board — where to deploy their team members. The Baltic SAREX 2014 (BS14) LICO left both his assistant and his tallyman on the lower decks, whereas the Baltic SAREX 2015 (BS15) LICO brought his assistant to the bridge and used the tallyman as a runner. This decision created different physical boundaries in 
which the teams could operate and different distances between the actors, both of which significantly affected their cue perception.

The LICOs needed to know when a unit (e.g., a firefighting team, a medical team, a damage control team) entered or left the ship, where it had been deployed and the progress it had made. The arrival of units was supposed to be communicated in advance, but the LICO would often learn of the arrival of new units after those entered the ship through the pilot door or when they made personal contact. Later, information was available at the place the unit had been deployed to. In addition, the LICOs needed to maintain control of the headcount on board and the state of passengers and crew. The wide dispersion of the LICO team during BS14 created wide physical boundaries within which the team could perceive cues. The BS14 LICO team had unit deployment well under control (as in sensemaking episode BS14_6, see Table 3), as the BS14 LICO assistant and tallyman were positioned on the lower decks and interacted with the arriving and departing units. In BS15, however, the LICO team experienced frequent problems with cue perception, as in the following episode:

After the LICO team, the first unit to arrive on board the BS15 vessel was a group of firefighters who came to the bridge to introduce themselves and inquire about their deployment (sensemaking episode BS15_3). The head of the firefighters and the LICOs discussed several options, including dispatching two men from the team as paramedics. The LICO ultimately discounted this plan, but the head of the firefighter missed this decision and left the bridge under the impression that two of his men should act as paramedics. Outside the view of the LICO, two firefighters prepared for paramedic duty. Some minutes later, the LICOs learned of injured persons in need of medical treatment (BS15_4), but as they were under the impression that there were no paramedics on board, they provided no aid. A bit later (BS15_5), one of the firefighters-turned paramedics came to the bridge asking for something to do.

As the cue (the firefighters preparing for paramedic duty) appeared outside the physical boundaries enacted by the LICOs, they were unable to use it in their sensemaking, which led to an inaccurate 
mental model that deprived them of an important resource. This was a consequence of having both the LICO and his assistant on the bridge, with the tallyman running between the lower decks and the bridge.

In addition, the tight physical boundaries in BS15 led to failure to initiate sensemaking, as the LICO team missed that the helicopters had arrived to evacuate passengers. In BS14, the LICO assistant and tallyman were located such that they could locally organise the hoisting in a timely fashion, and the LICO was able to easily coordinate the hoisting operations (BS14_3).

How and why did this important enactment decision take place? The situation unfolded as follows, depicted in Figure 5 .

As the BSI4 LICO boarded the ship, he found the pilot door unmanned and the entry deck largely empty, aside from crewmen some twenty metres away who aided injured colleagues (Figure 5, left, in the background). Searching for someone who could take him to the bridge, the LICO approached these crewmen who asked him to help with firefighting and aiding the injured. The LICO agreed and left his assistants there to help, after which a crewman guided the LICO to the bridge.

Figure 5

With this deployment, the LICO enacted wide physical boundaries that included both the bridge and pilot door, a critical spot where many of the cues appeared in the operation Although this enactment increased the distance between the LICO and the LICO assistant, the assistant could relay observations via radio so that cue perception was not impaired. The LICO did not seem to have made this decision with the intention to enact his spatial environment; rather, it was a side effect of a protocol violation by the crew that the pilot door must always be manned. If it had been manned, the LICO would not have become involved with the injured crewmen and would not have 
decided to leave his team on the lower decks, so the situation would probably have unfolded as it did in BS15:

When the BS15 LICO entered the ship, he found the pilot door manned with several crewmen and asked one of them to lead his team to the bridge (Figure 5, right). On the way, another crewman tried to engage and convince him to help with injured colleagues. The LICO, in passing, promised that help would come later and continued with his team to the bridge.

This led to a situation in which the BS15 LICO and his assistant were always, and the tallyman was often, on the bridge.

Both teams had radios, but the BS15 LICOs used them inconsistently. The BS15 tallyman walked from place to place on the ship, spending much time communicating face-to-face with the LICOs, which further compressed the physical boundaries in which the LICO team could perceive cues. Directly in front of them, the BS15 LICO team also had a large screen showing live footage from eight CCTV cameras of the vessel's aft and bow regions. Although these cameras showed footage of the boarding and disembarking activities and this footage appeared within their enacted spatial environment, the LICOs never used that information. Both LICO teams maintained their initial deployment throughout the operation.

\section{Enactment of space and cue processing}

The initial enactment decision that defined the physical boundaries of the LICOs' operation, i.e., the placement of the LICO team members, also had significant implications for cue processing. Wide (BS14) or tight (BS15) physical boundaries increased (BS14) or decreased (BS15) the LICO teams' cue processing capacities. Having an additional person on the bridge proved to be beneficial for cue processing during BS15, whereas the BS14 LICO often struggled with information overload, especially in the early stages of the operation. At times, the BS14 LICO received several parallel radio calls, which were more than he could handle. Radio calls also tended to interrupt discussions on the bridge during BS14. When the BS14 LICO was interrupted, he often lost his train of thought, which disrupted his sensemaking ability (BS14_8, BS14_9). During BS15, the 
LICO and LICO assistant were neither overloaded nor disrupted; when one person was on the radio, the other engaged in dialogue with other sensemakers, which the person on the radio could later rejoin. This improved their cue-processing capabilities. The following example juxtaposes cue processing during BS14 and BS15:

In episode BS14_4, the LICO assistant found persons suffering from smoke inhalation who required medical treatment. He informed the LICO via radio. The LICO discussed this information with the bridge crew. Paramedics were supposed to be in the vicinity, but no one on the bridge knew for certain if they were there. The LICO assistant, who had the best information but was on a lower deck, was disconnected from this discussion. Based on his exchange with the bridge crew, the LICO decided that the paramedics should address the situation. He then communicated this decision to the LICO assistant via radio.

In BS15_4, the tallyman found several persons in need of medical treatment. He went to the bridge to report this. The LICO, the LICO assistant, the tallyman and the master discussed the uncertainty regarding the number of injured persons and that the team knew of no paramedics on board. They decided that the tallyman should provide a clearer picture of how many persons required medical attention. The tallyman went to the lower decks to carry out the order.

The BS14 episode illustrates the drawbacks of wide physical boundaries for cue processing, as the distance between the LICO and LICO assistant prevented collective cue processing, and radio availability failed to mitigate this issue. The BS14 LICO assistant was disconnected and he remained disconnected throughout the entire exercise. To compensate for not having his assistant on the bridge, the BS14 LICO discussed matters with the bridge crew, especially the second officer. In contrast, the BS15 team minimised their physical distance (at the cost of tight physical boundaries) and could easily engage in collective cue processing.

Cue processing was also affected by a second important enactment decision: the workplace setup. The bridges were open and quiet work environments that imposed no physical boundaries for cue 
processing, but the ways in which the LICOs set up their workplaces created social boundaries that influenced their cue processing.

Upon entering the bridge, the BS14 LICO placed the notepad he carried on the first-best empty surface he found, a windowsill. As the bridge of the BS14 vessel is dominated by a large front window (Figure 3), its windowsill was a convenient place to deposit gear. This setup created significant challenges for collective cue processing. When the LICO was at his workplace, his back was to everyone else on the bridge. When he spoke with the master or the second officer, he could not see his notes. Thus, he created two disjointed workplaces with different social boundaries: one where he would work on his notes, which erected a social boundary by his needing to physically turn away from the others on the bridge, and the other where he engaged with others, which prevented him from referring to his notes. These social boundaries governed whether collective cue processing took place:

During passenger evacuation in BS14, the LICO had to establish a headcount on the ship to determine if persons were unaccounted for (BS14_5). The LICO, master, and second officer stood in the open space at the centre of the bridge, facing each other, discussing the information each of them had (Figure 6, left). During this discussion, the LICO wanted to take notes. Turning towards the windowsill where he had placed his notes, he turned his back to the master and second officer, at which point the master and second officer immediately stopped providing any form of input.

Figure 6

Comparable within-episode dynamics occurred repeatedly during BS14 (BS14_2, BS14_9, BS14_11).

When the BS15 LICO team entered the bridge, they found the safety plan laid out on the chart table, which was the first large empty surface they encountered. They placed their equipment there. 
When the BS15 LICO team members moved away from the chart table, stepping outside their enacted social boundaries, their cue processing capacities immediately diminished, as is evident in the following episode:

Figure 7

This sequence took place after the LICO team had learned that injured persons were not receiving necessary treatment (BS15_4) and held a briefing with the firefighting unit, whose members had understood (wrongly) that they were supposed dispatch personnel for paramedic duty (BS15_3). In BS15_5, one of the firefighters-turned paramedics came to the bridge to inquire about what he was supposed to do. He entered the bridge through a side entrance, which meant that he stood on the far side of the bridge as he tried to attract the LICOs' attention, separated by a railing and several metres of space from the table where the LICO team and the master where standing (far left in Figure 3, as depicted in Figure 7, right). The LICO assistant left the chart table and took a few steps in his direction to engage in a discussion. The LICO briefly glanced in his direction but did not engage. After their discussion, the LICO assistant sent the paramedic to a specific place on the ship, which was not where the injured persons were waiting for aid. Neither the LICO nor the master provided any input, and the LICO assistant did not communicate this deployment to the others. Fifteen minutes later, the paramedics returned to the bridge, complaining that they had nothing to do, this time entering through the main entrance and stepping towards the chart table, where they immediately had the full attention of both the LICO and LICO assistant. A harsh argument ensued, at the end of which the LICO ordered them to leave the ship. 
No comparable situations arose when actors remained within the enacted social boundaries (e.g., in BS15_7).

\section{Enactment of space and action}

By the nature of the LICOs' role, their actions included giving orders, relaying and following up on these orders. The LICOs' orders were shaped by their cue perception and cue processing, which were affected by how they had enacted their spatial environments, as well as by those aspects of their spatial environment that they could not influence. The ships were large, damaged and full of people, and these spatial properties shaped the actions the LICOs took.

However, how the LICOs enacted their spatial environments played a central role in their subsequent ability to relay and follow up on orders. The wide physical boundaries in BS14 meant that a member of the LICO team was often close to those receiving an order, which facilitated the flow of cues from the actions into continued sensemaking. For example, because the BS14 LICO assistant was located near the firefighters, he was able to convey the state of the firefighting unit back to the bridge without the confusion that occurred in BS15_3 and BS15_5.

The opportunities available to the LICOs to re-enact their spatial environment in relation to actions went underutilised. In BS15_3, the LICO appointed the head of the firefighting team that reported to the bridge as a sub-LICO for firefighting. As this person then went to fight the fire, he had no way to reach the LICO, so this appointment had no effect on the operation, and no attempts were made by either the LICOs or the firefighters to remedy this (such as the LICOs providing the firefighters with one of their spare radios).

\section{Mitigating the effects of space enactment}

We observed two instances in which the LICOs enacted their spatial environment that had strong and consistent effects on cue perception and cue processing and lesser, but still evident, effects on action. During the operations, it became quickly clear that the ability to perceive cues and act locally were important, as indicated by the continuous problems experienced by the BS15 LICO 
team. In addition, the social boundaries enacted on the bridge during BS14 were problematic, as the LICO struggled to balance working on his notes with talking to others on the bridge.

Surprisingly, although both LICOs experienced these problems directly and consistently, they never changed or 're-enacted' their spatial environments. The BS14 LICO did not opt to relocate his equipment — a notepad and two radios — during the three hours he worked on the bridge, although he could have moved them to a place that would have created more permeable social boundaries. For instance, the crew workplaces were arranged in a U-shape, much better suited to on-bridge communication (see Figure 3). It would have been just as easy for the BS15 LICO to deploy a person from his team permanently to the lower decks or to issue spare radios to a subLICO, which would have widened the team's physical boundaries and improved the ability of the team members to perceive cues and relay and follow up on orders. Instead, the sensemakers engaged in what we term 'mitigation activities,' i.e., activities that do not remedy but only temporarily mitigate problems posed by the spatial environment. These activities involved moving to or from a place, turning towards or away from others and seeking or avoiding the visual gaze of another.

During BS14, the LICO, the master and the second officer were continuously engaged in mitigation activities - trying to penetrate the boundaries the LICO's workplace setup had created. The BS14 LICO often moved between his two workplaces, walking three steps away from his notes, inviting a conversation or walking back to his notes (Figure 6, left). On several occasions, the master and second officer moved close to the LICO as he worked on his notes, at times as close as several centimetres, leaning into the LICO's field of view and trying with varying degrees of success to penetrate the LICO's social boundaries (Figure 6, right; BS14_6, BS14_7). In BS15, the tallyman was the one who moved between the bridge and other locations on the ship. For example, in BS15_8, a crewman who was evacuating passengers from the pilot door asked the tallyman if another vessel could come close to the ship to speed up the evacuation process. The tallyman went to the bridge to relay this question to the LICO. 
These mitigating activities occurred in response to the need of the moment but were not connected with a broader concept of how space should generally be enacted to facilitate sensemaking. They temporarily reshaped the spatial environment, producing the 'lived' environment in which individual sensemaking episodes took place. This lived environment was fluid and continuously recreated yet firmly embedded within the constraints of the initial enactment decisions.

Several indications suggest that the surprising lack of any re-enactment of the spatial environment was caused by the limited cognitive control both LICOs displayed regarding how they enacted space. First, the critical decisions that led to the enactment of the physical and social boundaries were made incidentally, and the LICOs did not display that they put any thought into these decisions or considered revising them. In BS15, for example, the LICOs never discussed the merits or drawbacks of appointing the runner or the LICO assistant to the lower decks, even after it became clear that they had problems perceiving relevant cues. Second, due to the nature of the exercise design, the LICOs were in a high-pressure situation that was outside their established work pattern. They were required to process new information and quickly devise courses of action, which occupied them throughout the observation period. The LICOs were also unfamiliar with their spatial environments, which added to their cognitive load.

The heaviness of the LICOs' cognitive load was also made evident in their use of artefacts. The BS15 LICO team ignored a large screen with relevant CCTV footage throughout the entire exercise and the spare radios they could have used to improve their cue perception and control. Engaging with an unfamiliar device (the large CCTV screen is not standard equipment on the bridges of smaller authority vessels) or using artefacts in nonstandard ways (radios are not customarily issued to non-crew members) seemingly exceeded the available cognitive capacities of the LICOs.

Instead of re-enacting their spatial environment, the LICOs focused on the issues at hand. The movements they used to mitigate the problems arising from their spatial enactment required litile to no cognitive effort, as turning to others on the bridge or instructing the movements of the runner were intuitive and obvious activities, given the boundaries they had enacted. The sensemakers seemingly accepted the outcome of their spatial enactments as a given; they worked around the 
Actors in high-reliability organisations work in spatial environments that shape what they need to do and can do. In our case, this included the layout of the distressed vessel and the locations of the people and hazards on board. We call this the 'unenacted physical space.' Parts of the unenacted physical space are outside of the actors' contro1. In our case, the actors could not influence where the fire had broken out or where the evacuation and entry points were. Other parts are under the actors' control. In the exercises, the actors could influence where team members were stationed and how they set up their workplace. Actors enact a subsection of the unenacted physical spaceintentionally or unintentionally_delimitating physical and social boundaries and the spatial relation between people and objects, creating an 'enacted space'.

Within this enacted space, actors engage in discrete activities dictated by the needs of the moment to create the 'lived space' in which sensemaking episodes take place. These mitigation activities both influence and arise from individual sensemaking episodes. In our case, we see an example of this when the BS14 LICO struggled to obtain an accurate headcount (BS14_6, BS14_7), which prompted the master of the distressed vessel and the second officer to temporarily breach the social boundary erected by the LICO by physically leaning into his field of view. This behaviour affected the LICO's cue processing, which led to further mitigating activities, such as the LICO then 
walking over to the second officer to continue the discussion. In that way, the 'lived' physical space is continuously reproduced without altering the overarching enactment. This model depicts how actors produce their lived spatial environment and outlines how sensemaking and the enactment of space influence and shape each other.

\section{Discussion}

Previous research on sensemaking in high-reliability task contexts modelled space as a physical property residing outside the sensemakers' control (Cornelissen et al., 2014; Maitlis \& Christianson, 2014; Schakel et al., 2016). In that sense, space is a 'container' for sensemaking (Stephenson et al, 2020). By studying the actions of sensemakers under high cognitive loads, we can expand this understanding. Our findings, condensed into the model shown in Figure 8, provide a tentative theory for the underlying mechanics that link sensemaking and the enactment of space. We differentiate between unenacted, enacted and lived space and between activities that enact space and those that mitigate the effects of how space has been enacted. In the section below, we discuss the implications for research on space in sensemaking, space and organising and managerial practice in high-reliability organisations.

\section{Contributions to research on space and sensemaking}

Our study advances the enactment perspective in sensemaking research (Christianson, 2019; de Rond et al., 2019; Introna, 2019). Previous research on sensemaking in high-reliability task contexts outlines the enactment of cognitive frames and coordination but largely considers space to be a property of the environment (Cornelissen et al., 2014; Schakel et al., 2016; Weick, 1993). Our data show that this perspective disregards an important aspect of sensemaking in highreliability task contexts. Our data indicate that the process through which space is enacted follows a sequence in which enactment decisions produce an 'enacted space' whose effects are then mitigated by microactivities to create a 'lived space'. In this lived space, sensemaking episodes take place, and a recursive loop occurs between sensemaking and activities that mitigate the effects of the enacted space. The notion of an unenacted, enacted and lived space evokes Lefebvre's conception of space as conceived, perceived and lived, which has guided research on space and 
organising (Giovannoni \& Quattrone, 2018; Sivunen \& Putnam, 2019; Taylor \& Spicer, 2007). Our model deviates from this concept in an important way; sensemakers in our field work in their spatial environment only for a short period of time, not long enough to create a lived space in Lefebvre's sense, which arises from repeated interactions with the spatial environment. Instead, sensemakers create their lived space by modifying the space they have enacted through microactivities that temporarily reshape boundaries and distances. Our paper thus extends previous theories regarding the mechanisms through which the enactment of space and sensemaking interrelate

Our findings suggest that actors who experience high cognitive load have little control over how they enact space. When an enacted space is subsequently found to be problematic, they engage in mitigating activities rather than re-enacting their spatial environment. We theorise that this indicates nested sensemaking, where sensemaking episodes, i.e., 'imminent sensemaking' in the terminology of Sandberg and Tsoukas (2020), are nested in the overall mental model of an operation. Sensemaking is, as noted by Weick et al. (2005), 'an ongoing, unknowable, unpredictable streaming of experience in search of answers to the question, "what's the story?"' (p. 410). Our findings indicate that the way in which sensemakers enact space quickly becomes part of their 'story' of an operation. For the sensemakers in our study, the 'story' was shaped by having their gear in one place and their colleagues somewhere else. How their space was enacted was at times problematic, but there were no cues that would have challenged the plausibility of this mental model of how space 'was' in this operation. Sensemaking theory has hinted at different layers of sensemaking (Harris, 1994; Sonenshein, 2016), but the idea of nested sensemaking has never been integrated into the conceptual framework. We propose an expansion of this concept that aiso paves the way for future research to elaborate upon nested sensemaking in other areas.

With these contributions, our study resolves a conceptual disconnect between sensemaking research, which treats space as external to the actor, and the literature on space and organising, which considers space to be a simultaneously organised and organising entity (Beyes and Holt 
2020). We suggest that sensemaking theory can enhance its explanatory power by moving towards the enactment perspective and provide a theoretical basis for such a development.

\section{Contributions to research on space and organising}

Our theorisation has implications beyond sensemaking research. The notion that space and organisation are inherent aspects of each other has led researchers to explore the mechanisms underlying their relationship (Cnossen \& Bencherki, 2019; Giovannoni \& Quattrone, 2018; Lee, 2019: Ratner, 2020; Stephenson et al., 2020). Our study expands upon this approach. Our study adds cognitive load as a contingency condition that leads to a novel distinction among unenacted, enacted and lived space and helps us to better understand the relationship between space and organising.

Previous work on space and organising indicates that individuals enact their spatial environment often quite purposefully and create a lived space over time based on needs and power relations (Beyes \& Holt, 2020; Cnossen \& Bencherki, 2019; Sivunen \& Putnam, 2019). That research, however, pertains to individuals who act in familiar spatial environments with low cognitive load and over prolonged periods of time. In such situations, a centrally positioned trailer can become a meeting point, as individuals go there repeatedly to fetch a coffee (Cnossen \& Bencherki, 2019). Our study suggests that when the cognitive load is high and the exposure to the spatial environment is short-term, the interaction between space and organising is incidental instead of purposive, and re-enactment of space is replaced by temporary mitigation activities. This produces a different kind of lived space, one that is recreated in short intervals based on the needs of the moment rather than socially produced over repeated interactions and prolonged periods of time.

\section{Contributions to research on high-reliability organisations}

Our findings indicate that high-reliability organisations can improve their performance in relation to how they enact space. In our case, sensemakers enacted space incidentally and failed to comprehend the effect this had. This oversight was a consequence of their high cognitive load, yet as noted in previous research, training can help actors in high-reliability organisations overcome 
issues that arise due to situational complexity (Steigenberger, 2016). Sensitizing sensemakers to the effect of their enactment of space should be both straightforward and helpful.

Our case demonstrates the important trade-off between strengthened cue processing associated with tight physical boundaries and strengthened cue perception associated with wide physical boundaries. Many sensemaking tools in high-reliability organisations are predominantly designed to encourage discussion by increasing actor proximity (Chapman, 2009; Wiener, Kanki and Helmaich, 1993), which can lead to the unintentional loss of information, either because the tools encourage actors to fail to be where the cues are or because they overemphasise discussion at the expense of remaining sensitive to emerging cues. This issue is relevant when actors are under high cognitive load in unfamiliar spatial environments. This is typically not the case in the fields for which such tools were designed. Cockpit resource management, for example, is designed for the stable and well-known spatial environment of an airplane cockpit, yet the tool is used well beyond this field (Salas, Wilson, Burke and Wightman, 2006). This might explain why tools such as cockpit resource management sometimes fail to improve performance when applied in other types of high-reliability organisations (Helmreich \& Merritt, 2017).

Our findings also shed light on the limitations that habitual action patterns can impose on the sensemaking processes of actors. We found that under a high cognitive load, sensemakers used only familiar artefacts and ignored those that were unfamiliar Overreliance on habitual action patterns is a known source of error in high-reliability task contexts (Catino \& Patriotta, 2013). Our findings indicate that this effect relates to suboptimal decisions regarding how space is enacted and that its effects are mitigated, which could also be addressed by appropriate training.

\section{Limitations and directions for future research}

We studied sensemakers who experienced a high cognitive load and worked in an unfamiliar spatial environment. We expect actors to exhibit more control over how they enact space when they have a lower cognitive load. Future research might test if this assumption holds true. In addition, future research might also study the enactment of space in environments where the cognitive load is high but where the actors work in a well-known spatial environment, such as the control room of a 
nuclear power plant (Stachowski, Kaplan and Waller, 2009) or a space mission control room (Dunbar \& Garud, 2009). We also note that our study took place in a specific setting, maritime SAR, and unobserved contingencies such as the field culture might have affected our observations. An interesting line of research that was beyond the focus of our study is the intersection of time and space in sensemaking. In our study, cues were visible only at specific times and were missed if actors were not physically present at that time. Actors seemed to have also enacted time by pacing or sequencing. It would be valuable to gain a better understanding of the relation between time and space in sensemaking processes.

\section{Conclusion}

Space is not exogenous to the sensemaking process; it is enacted by sensemakers, which shapes whether and how they perceive cues, process cues and act on the mental models they develop. In this study, we found that sensemakers under high cognitive load were unable to consciously enact and later re-enact their spatial environments, even when the way they had enacted their spatial environment proved detrimental to their sensemaking processes. The model we developed provides a theoretical frame for these observations and paves the way towards a better understanding of how space and sensemaking interact in shaping the performance of actors in high-reliability task environments. 
Figures and Tables
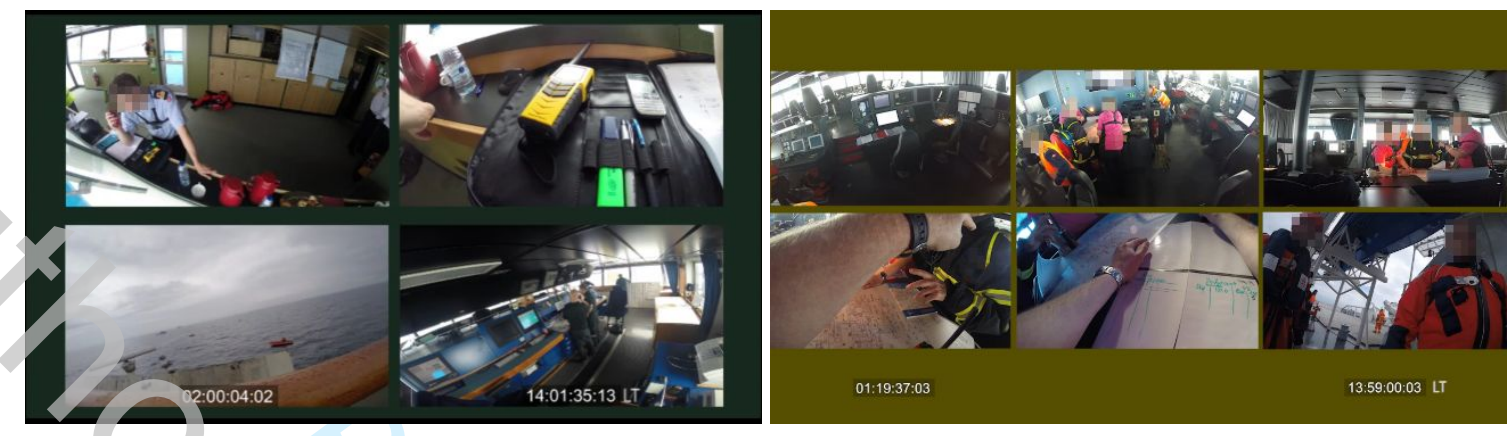

Figure 1: Camera setup at Baltic SAREX 2014 (left) and Baltic SAREX 2015 (right) ${ }^{2}$ 

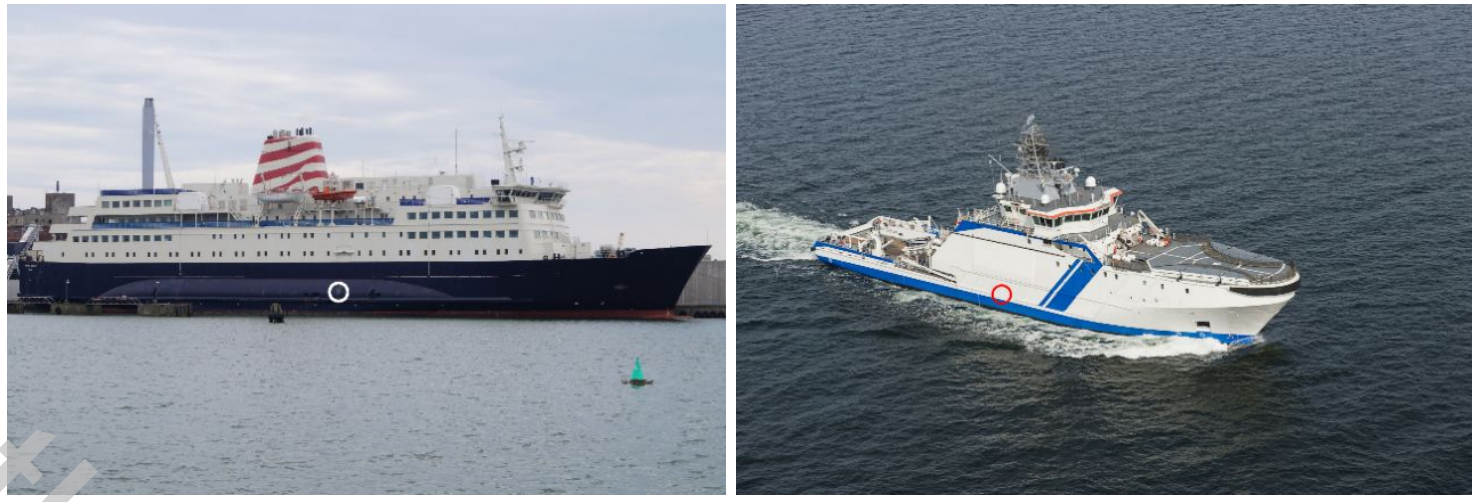

Figure 2: Vessel in distress in Baltic SAREX 2014 (left) and Baltic SAREX 2015 (right) $^{3}$ 


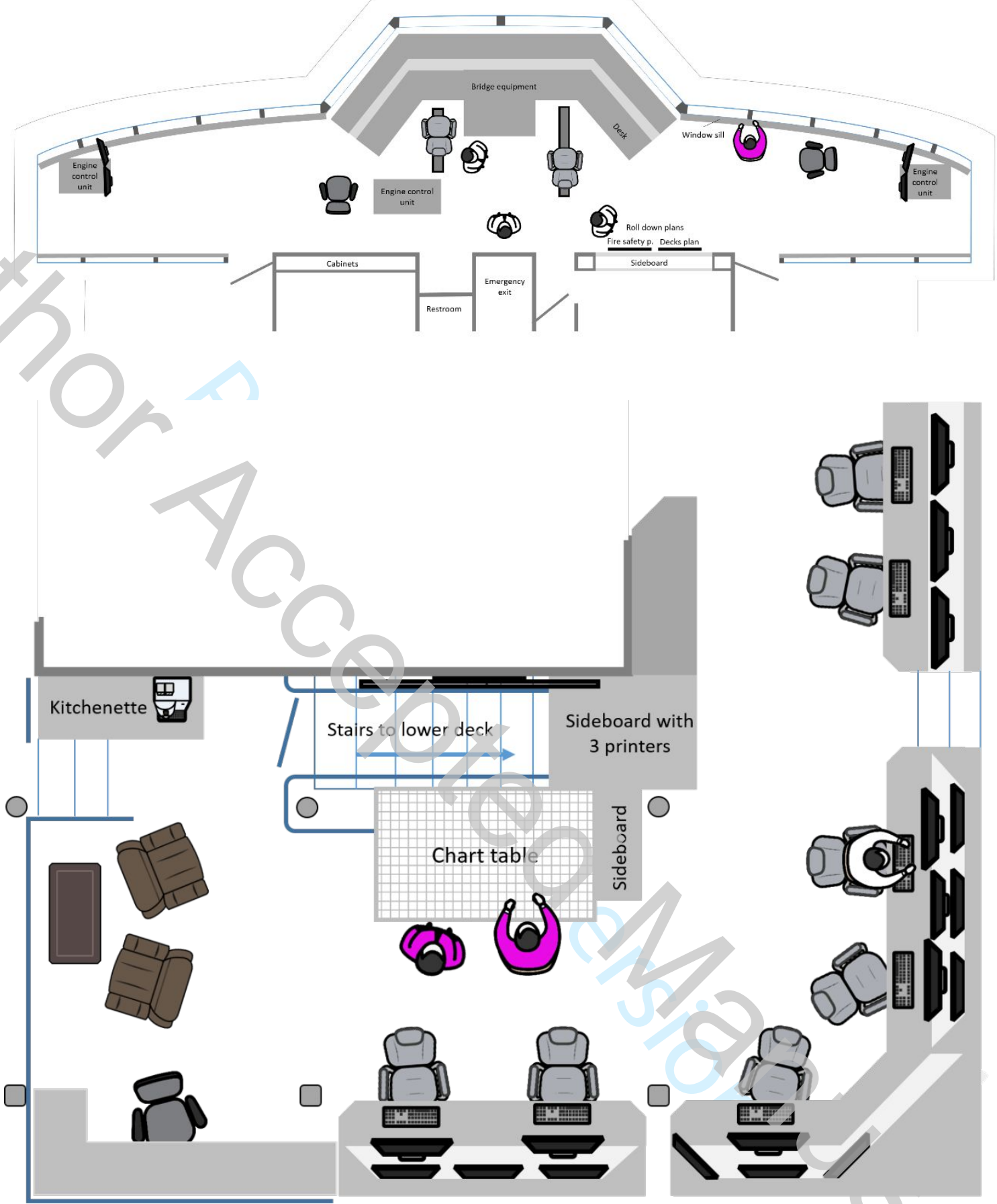

Figure 3: Bridge layout in Baltic SAREX 2014 (top) and Baltic SAREX 2015 (bottom). Bridge crew in white shirts, LICOs in pink shirts. 

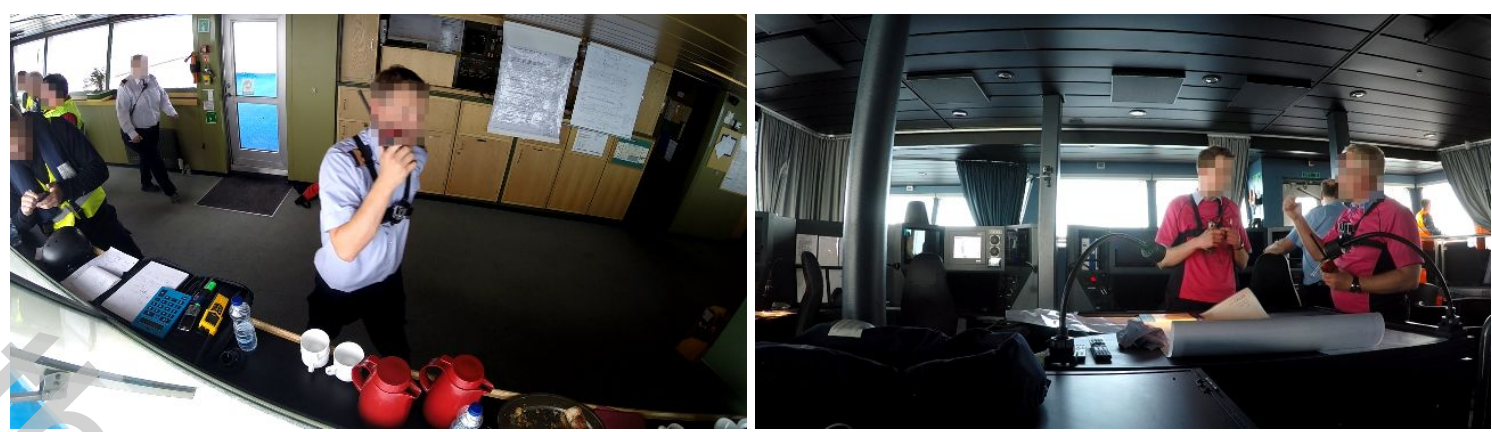

Figure 4: LICO communicating with LICO assistant in BS14 and BS15 (images obtained by stationary bridge camera). 

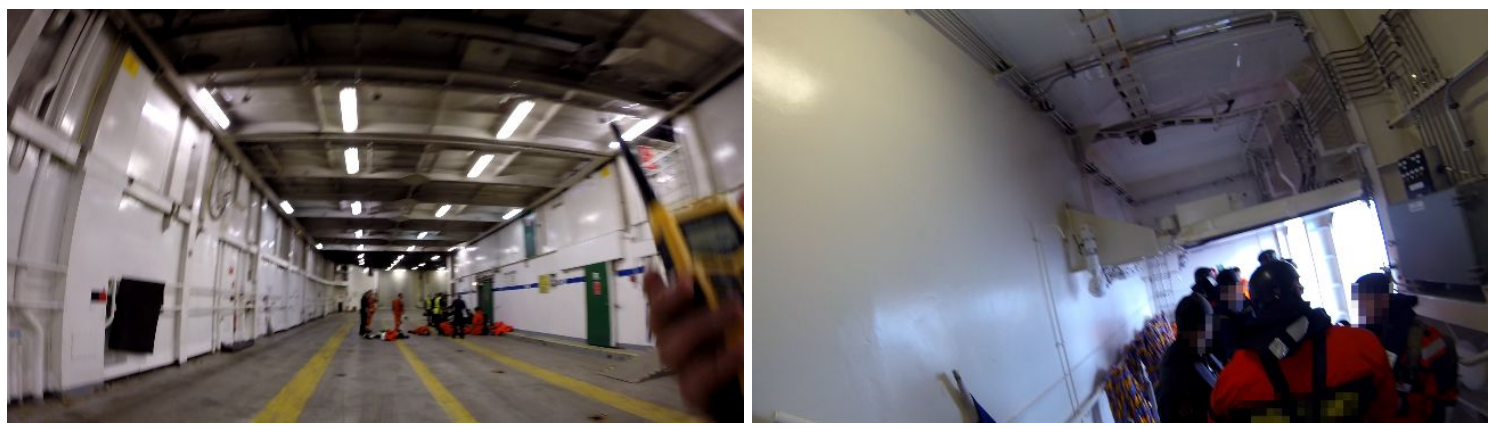

Figure 5: Ship's entry deck, BS14 (left) and BS15 (right) (images obtained by LICO body cameras). 


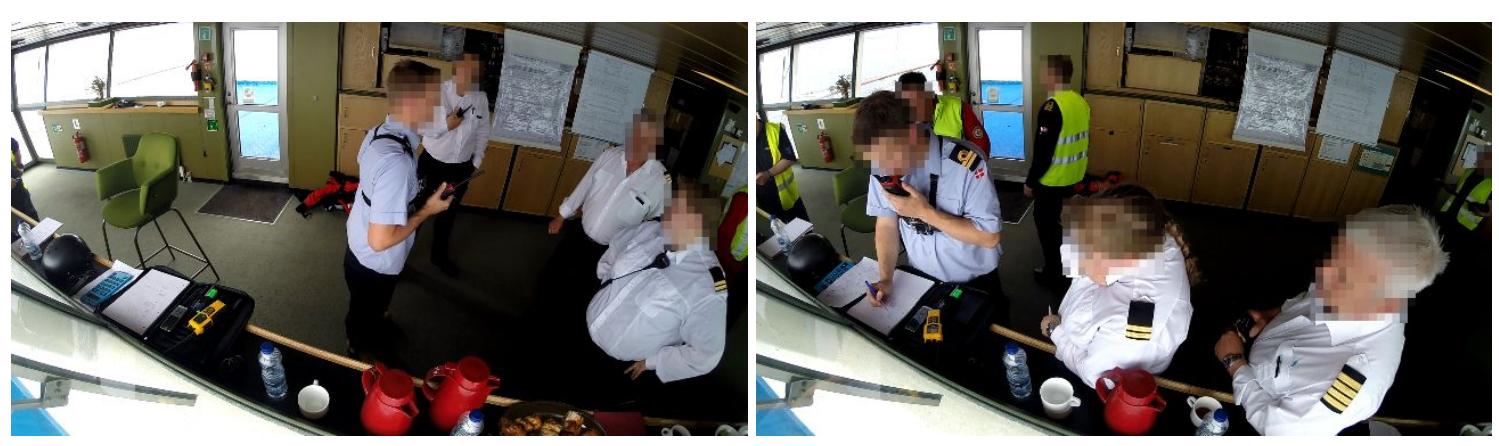

Figure 6: LICO workplace in BS14 (images obtained by stationary bridge camera).

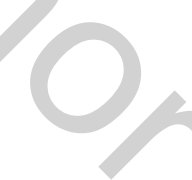

20

21

22

23

24

25

26 


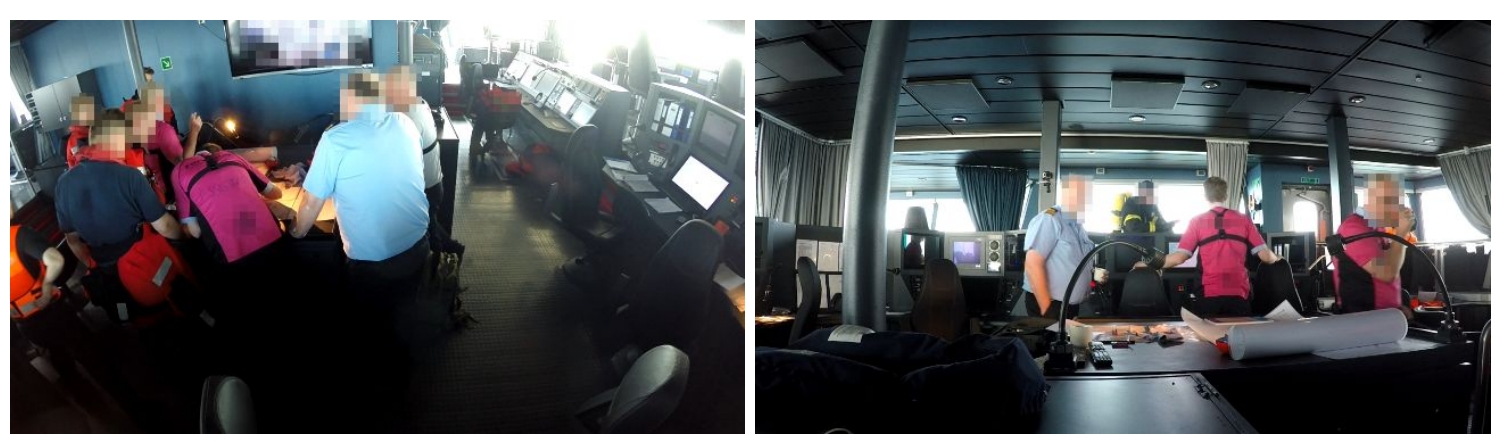

Figure 7: LICO workplace in BS15 (images obtained by stationary bridge camera).

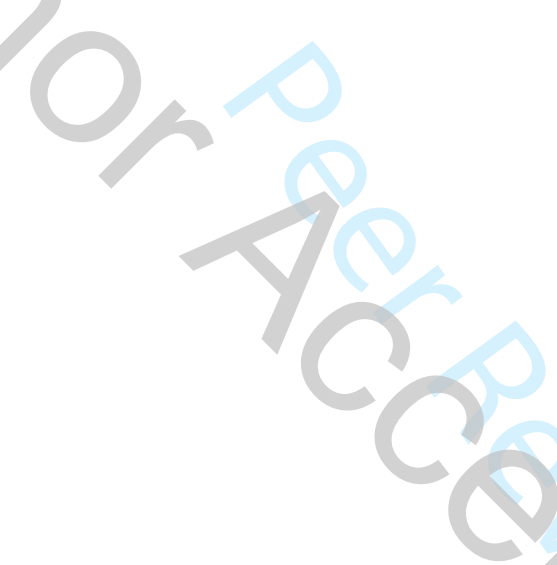




\section{Figure 8: Space and sensemaking in high-reliability task contexts.}


Table 1: Data Sources and Use

\begin{tabular}{l}
\hline Data Source \\
Participant observation in real- \\
life SAR operations (4 days, \\
second author); introductory \\
training to SAR techniques, \\
regulations and procedures (1 \\
day, both authors). \\
Video data (2,360 min of videos, \\
aligned into two streams of $4 \mathrm{~h} 55$ \\
min each, 122 pages of \\
transcripts of verbal \\
communication, separate audio \\
channels for each camera).
\end{tabular}

Type of Data

Education, observations and informal interviews.
Baltic SAREX 2014: body camera LICO; body camera umpire; stationary camera bridge.

Baltic SAREX 2015: body camera LICO; body camera LICO assistant; 3 stationary cameras on the bridge.

Observations $(540 \mathrm{~min}$ of The second author was part of the participant observation during planning committee of the the exercises, $30 \mathrm{~h}$ of exercise. Data are observational development work on the with field notes.

exercise).

Interviews $(16 \mathrm{~h}$ formal Three formal interviews on interviews, approx. $10 \mathrm{~h}$ informal exceptional operations with interviews).

Secondary data (300 pages).

\section{experienced maritime SAR} personnel, approximately $2 \mathrm{~h}$ each.

One formal interview (approximately 8 h) with the person responsible for the LICO role in the Royal Danish Navy and a senior umpire (group interview), during which we watched video footage of BS14 and developed a shared understanding of occurrences and decisions made. Approximately $10 \mathrm{~h}$ of informal interviews, with umpires and exercise participants.

IMO guidelines for mass rescue operations, Baltic SAREX 2014 and 2015 exercise orders, guidelines of the Royal Danish Navy on the LICO role, planning documents for Baltic SAREX 2014 and 2015.
Use in the Analysis

Familiarization with the field, its standards and regulations.

The videos were aligned as timesynchronised split-screen video streams, which were then abductively coded.

Input to coding and interpretation of results.

Familiarization with the field and the sensemaking requirements in non-routine operations.

Development of coding scheme, validity check and in-depth insights into the requirements of the LICO role in the exercise, identification of sensemaking episodes.

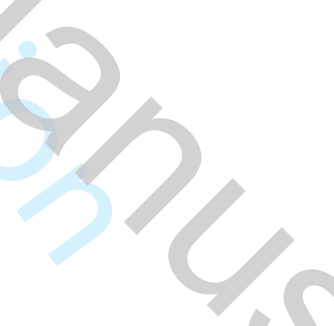

Background information on rules, guidelines and routines as well as the exercises. 


\section{Table 2: Operation Rundown}

\begin{tabular}{|c|c|c|c|c|}
\hline Stage & Key events Baltic SAREX 2014 & $\begin{array}{l}\text { Operation } \\
\text { time (h:min) }\end{array}$ & Key events Baltic SAREX 2015 & $\begin{array}{l}\text { Operation } \\
\text { time (h:min) }\end{array}$ \\
\hline \multirow[t]{4}{*}{ Boarding } & $\begin{array}{l}\text { LICO, LICO assistant and tallyman enter the distressed } \\
\text { vessel, pilot door is unmanned. }\end{array}$ & $0: 39$ & $\begin{array}{l}\text { LICO, LICO assistant and tallyman enter the distressed vessel, } \\
\text { pilot door is manned, they ask to be guided to the bridge. }\end{array}$ & $0: 36$ \\
\hline & $\begin{array}{l}\text { LICO walks towards a group of injured and uninjured } \\
\text { crew members, receives information: fire onboard, } \\
\text { injured people. }\end{array}$ & $0: 41$ & They pass injured people who ask for help. & $0: 37$ \\
\hline & $\begin{array}{l}\text { LICO leaves LICO assistant and tallyman with this } \\
\text { group and proceeds to the bridge. }\end{array}$ & $0: 42$ & $\begin{array}{l}\text { LICO leaves the tallyman on the lower decks, who will later act } \\
\text { as a runner. }\end{array}$ & $0: 37$ \\
\hline & $\begin{array}{l}\text { On the bridge, he introduces himself to the bridge crew, } \\
\text { obtains an initial briefing. Asks about assembly points } \\
\text { and the safety plan. }\end{array}$ & $0: 44$ & $\begin{array}{l}\text { LICO and LICO assistant reach the bridge, introduce themselves } \\
\text { to the bridge crew. }\end{array}$ & $0: 41$ \\
\hline \multirow[t]{2}{*}{$\begin{array}{l}\text { Initial } \\
\text { actions }\end{array}$} & $\begin{array}{l}\text { LICO and master discuss the situation, LICO learns } \\
\text { about ship layout and evacuation and assembly points. }\end{array}$ & $0: 50$ & $\begin{array}{l}\text { LICO engages in discussion with bridge crew, obtains initial } \\
\text { headcount and damage evaluation. Discussion of evacuation } \\
\text { points. }\end{array}$ & $0: 47$ \\
\hline & $\begin{array}{l}\text { Establishing headcount, several persons missing, } \\
\text { others seriously injured. }\end{array}$ & $0: 54$ & Discussion with on-scene coordinator on priorities. & $1: 00$ \\
\hline \multirow[t]{3}{*}{ Coordination } & First helicopter arrives, hoisting operations begin. & $0: 53,0: 59$ & $\begin{array}{l}\text { First helicopter arrives, but no hoisting operation takes place as } \\
\text { no passengers had been prepared for evacuation. Evacuation via } \\
\text { boat begins. Hoisting operations begin some minutes later. }\end{array}$ & 1:01 \\
\hline & Damage control team arrives. & $0: 59$ & $\begin{array}{l}\text { LICO learns that the ship carries dangerous goods, which turn out } \\
\text { to be methane gas. }\end{array}$ & 1:05 \\
\hline & $\begin{array}{l}\text { Firefighting team arrives. LICO delegates coordination } \\
\text { to LICO assistant. }\end{array}$ & $1: 08$ & $\begin{array}{l}\text { First firefighters arrive, receive a briefing on the bridge. The } \\
\text { firefighters misunderstand orders, split up and some prepare for } \\
\text { paramedic activities. }\end{array}$ & $1: 12$ \\
\hline 37 & & Organizat & Studies & \\
\hline
\end{tabular}


New units arrive; medical team receives briefing on the bridge and is then dispatched to establish an overview

$1: 18,1: 23$ of the number of injured persons on board.

Persons suffering from smoke inhalation found, 1:32 requiring immediate medical attention.

Fire extinguished.

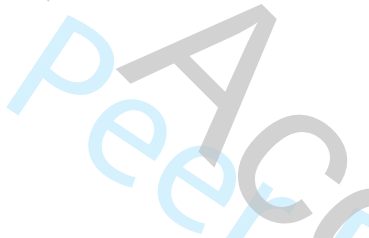

Headcount reveals that there are still 16 persons 1.56 unaccounted for. Firefighters search the ship.

Ship is declared technically safe.

The last missing person is found, exercise ends soon after.
Ship develops a list (not simulated in the exercise), as there is stil no damage control team in place. Injured people throughout the ship.

On-scene coordinator complains that they received no information about how many people had left the distressed vessel. LICO has no reliable information.

Fire extinguished, one missing person found. Vessel list is now so severe that hoisting operations from the aft deck are no longer possible.

More medical personnel arrive on board, LICO delegates their ir $2: 28$ coordination to the tallyman.

Despite the absence of a damage control team, the exercise staff define the hole in the hull as closed and allows hoisting operations to continue.

LICOs initiate systematic search for the remaining missing persons.

First damage control team arrives.

All missing persons are found, exercise ends soon after. 


\section{Table 3: Sensemaking Episodes}

\begin{tabular}{|c|c|c|c|c|}
\hline $\begin{array}{l}\text { Sensemaking } \\
\text { episode }\end{array}$ & $\begin{array}{l}\text { Start and end time } \\
\text { (operation time) }\end{array}$ & $\begin{array}{l}\text { Situation on board and sensemaking } \\
\text { trigger }\end{array}$ & Sensemaking content & Sensemaking outcome \\
\hline BS14_1 & $\begin{array}{l}00: 41: 48- \\
00: 43: 02\end{array}$ & $\begin{array}{l}\text { LICO enters the ship and sees firefighters } \\
\text { and injured persons. }\end{array}$ & $\begin{array}{l}\text { Establishing priorities, committing } \\
\text { LICO team. }\end{array}$ & $\begin{array}{l}\text { LICO leaves LICO assistant and tallyman on the } \\
\text { car deck, concludes that firefighting is critical } \\
\text { and communicates this to the mother ship. }\end{array}$ \\
\hline BS14_2 & $\begin{array}{l}00: 44: 00- \\
00: 54: 02\end{array}$ & $\begin{array}{l}\text { LICO arrives on the bridge and must } \\
\text { establish an overview of the situation. }\end{array}$ & $\begin{array}{l}\text { Priorities, definition of collection } \\
\text { points for triage and evacuation. }\end{array}$ & $\begin{array}{l}\text { Assembly points established; an initial overview } \\
\text { of the situation is reached. Plan for commitment } \\
\text { of firefighters. }\end{array}$ \\
\hline BS14_3 & $\begin{array}{l}01: 04: 54- \\
01: 05: 35\end{array}$ & Helicopter arrives on the scene. & Hoisting operations. & $\begin{array}{l}\text { Plan for hoisting operations is established, } \\
\text { hoisting can start. }\end{array}$ \\
\hline BS14_4 & $\begin{array}{l}01: 15: 36- \\
01: 16: 40 \\
\text { Continued: } \\
01: 18: 58- \\
01: 20: 00\end{array}$ & $\begin{array}{l}\text { People suffering from smoke inhalation } \\
\text { are located; mother ship requests } \\
\text { headcount. }\end{array}$ & $\begin{array}{l}\text { Establishing headcount and initial } \\
\text { evaluation of injured persons: is more } \\
\text { help needed? }\end{array}$ & $\begin{array}{l}\text { No extra resources needed; victims can be } \\
\text { treated by the available paramedics. }\end{array}$ \\
\hline BS14_5 & $\begin{array}{l}01: 32: 59- \\
01: 37: 13\end{array}$ & $\begin{array}{l}\text { Suspicion that there are still unaccounted } \\
\text { persons on board. }\end{array}$ & $\begin{array}{l}\text { Establishment of a more accurate } \\
\text { headcount. }\end{array}$ & New headcount. \\
\hline BS14_6 & $\begin{array}{l}01: 43: 49 \\
01: 44: 58\end{array}$ & $\begin{array}{l}\text { More firefighters are arriving on board. } \\
\text { Mother ship enquires about how many } \\
\text { rescue personnel had arrived. Conflicting } \\
\text { information. }\end{array}$ & $\begin{array}{l}\text { Number and origin of external } \\
\text { personnel on board. }\end{array}$ & Crew had the correct number, which is 12 . \\
\hline BS14_7 & $\begin{array}{l}01: 46: 47- \\
01: 47: 35\end{array}$ & $\begin{array}{l}\text { Further confusion about the headcount } \\
\text { during a situation report: Conflicting } \\
\text { numbers between LICO and crew. }\end{array}$ & $\begin{array}{l}\text { Resolving the conflicting information } \\
\text { regarding the headcount. }\end{array}$ & $\begin{array}{l}\text { The crew's number is likely correct, the LICO } \\
\text { settles for this number and discards his previous } \\
\text { count. }\end{array}$ \\
\hline BS14_8 & $\begin{array}{l}01: 49: 58- \\
01: 52: 33\end{array}$ & $\begin{array}{l}\text { LICO assistant reports that there is a } \\
\text { seriously injured person in need of } \\
\text { immediate help on the car deck. }\end{array}$ & $\begin{array}{l}\text { What to do with this person? Where } \\
\text { are the medics? What medical } \\
\text { resources are still available? Is a } \\
\text { helicopter available? }\end{array}$ & $\begin{array}{l}\text { Person should be evacuated as fast as possible by } \\
\text { boat. }\end{array}$ \\
\hline
\end{tabular}




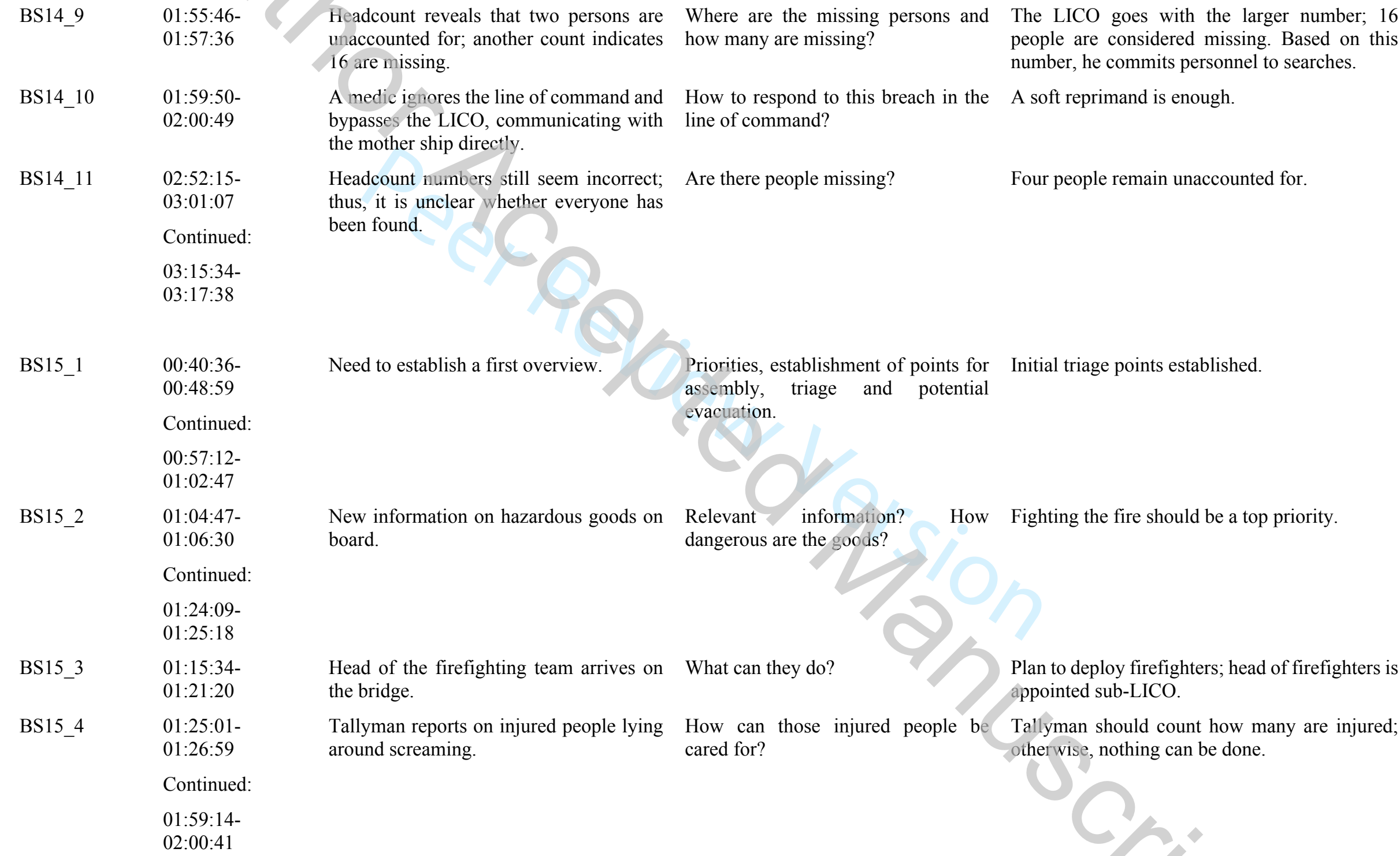

BS14 9 01:55:46$01: 57: 36$

BS14_10 01:59:5002:00:49

BS14_11 02:52:1503:01:07

Continued:

03:15:34-

03:17:38

BS15_1 00:40:36-

00:48:59

Continued:

00:57:12-

01:02:47

BS15_2 01:04:47-

01:06:30

Continued:

01:24:09-

01:25:18

BS15_3 01:15:34-

01:21:20

BS15_4 01:25:01-

01:26:59

Continued:

01:59:14-

02:00:41

Headcount reveals that two persons are unaccounted for; another count indicates 16 are missing.

A medic ignores the line of command and bypasses the LICO, communicating with the mother ship directly.

Headcount numbers still seem incorrect; thus, it is unclear whether everyone has

been found.

Where are the missing persons and how many are missing?

How to respond to this breach in the line of command?

Are there people missing?

Need to establish a first overview. . Priorities, establishment of points for assembly, triage and potential evacuation.

New information on hazardous goods on board.

Relevant information? dangerous are the goods?

How

Fighting the fire should be a top priority.

Head of the firefighting team arrives on What can they do? the bridge.

Tallyman reports on injured people lying around screaming.

How can those injured people cared for?

The LICO goes with the larger number; 16 people are considered missing. Based on this number, he commits personnel to searches.

A soft reprimand is enough.

Four people remain unaccounted for.

Initial triage points established. 


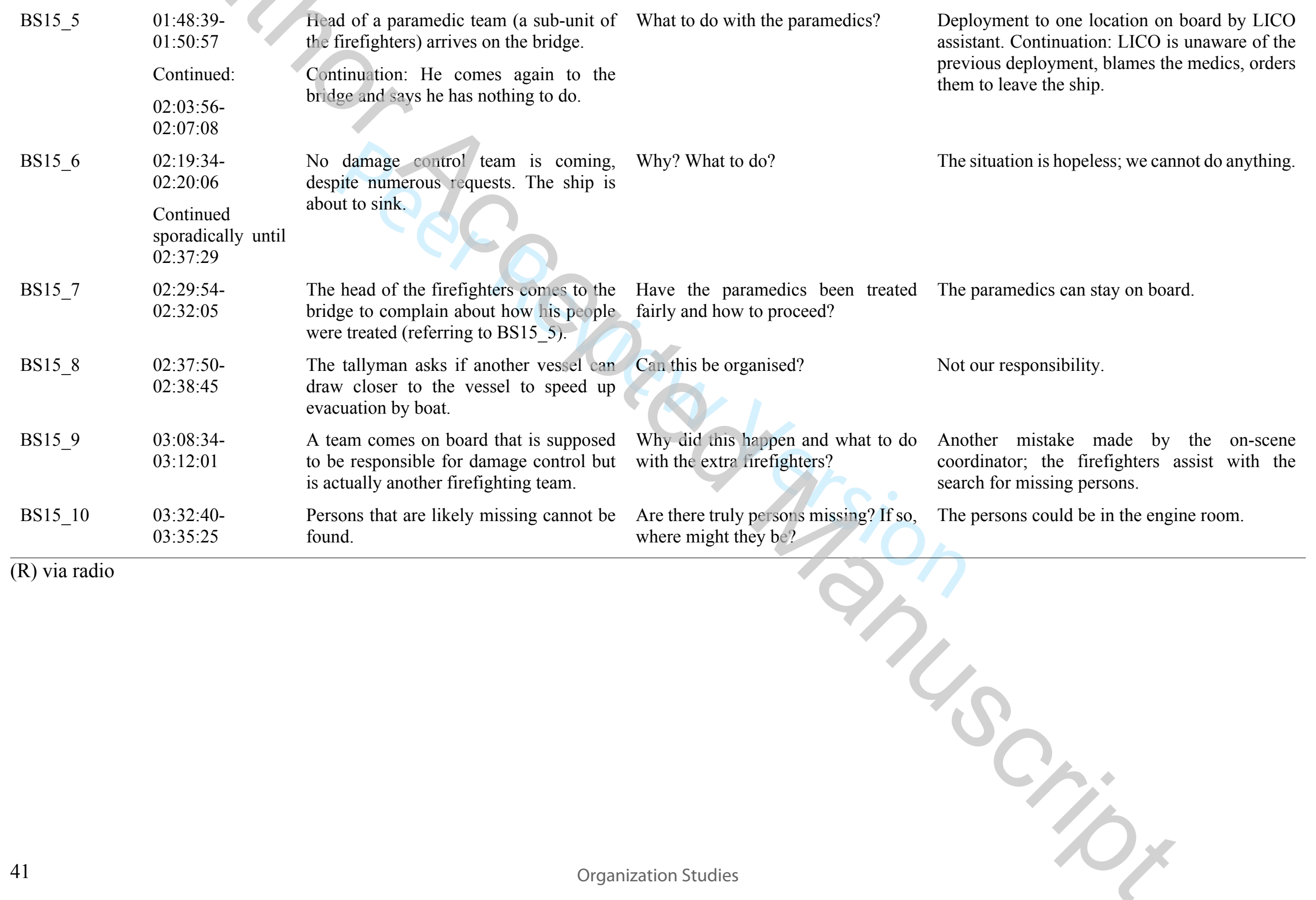


1: Weinfurtner and Seidl (2019) also suggest mental boundaries as a relevant dimension of space that determines status and identity. We found no instances in our data in which such mental boundaries would play a role; thus, they do not feature in our analyses.

2: The cameras are (from top left to lower right) Baltic SAREX 14: Stationary camera distressed vessel bridge, body camera LICO, body camera umpire, stationary camera on-scene coordinator vessel bridge (not used for this analysis); Baltic SAREX 15: First stationary camera distressed vessel bridge, second stationary camera distressed vessel bridge, third stationary camera distressed vessel bridge, body camera LICO, body camera LICO assistant, body camera below-ship observations (not used for this analysis). The left-hand number indicates the mission time, and the right-hand number is the local time. In the BS14 video, the LICO is the person in the blue shirt. In the BS15 footage, the persons in the pink shirts are the LICO and LICO assistant.

3: The left photo is used under the Creative Commons licence. The right photo is an anonymised image provided by the Finnish Border Guard for the purpose of this publication. 


\section{Acknowledgements}

We would like to thank the participants of Baltic SAREX 2014 and 2015. Special thanks are due to the Royal Danish Navy and the Finnish Border Guard, Jens Sejerskjold Sørensen, Rolf Detlefsen, Anders Elgaard, Fredrik Forsman, Jörg Kemna, Scott MacKinnon, Bjarne Toft Madsen, and Anders Møller. We thank Marlys Christianson, Zeki Simsek, Jason Shaw and Hendrik Wilhelm as well as participants in a research seminar at Jönköping International Business School for helpful comments on earlier versions of this manuscript. Finally, we are indebted to our editor, Renate Meyer, and three anonymous reviewers, for their constructive feedback during the revision process.

\section{Funding}

This research was funded by the German Federal Ministry of Education and Research under Grant No. 13 N12106 and 13N12107. 


\section{References}

Beane, Matt \& Orlikowski, Wanda J. (2015). What difference does a robot make? The material enactment of distributed coordination. Organization Science, 26, 1553-1573.

Beyes, Timon \& Holt, Robin (2020). The topographical imagination: Space and organization theory. Organization Theory, 1, 1-26.

Catino, Maurizio \& Patriotta, Gerardo (2013). Learning from errors: Cognition, emotions and safety culture in the Italian Air Force. Organization Studies, 34, 437-467.

Chapman, Kimberly B. (2009). Improving communication among nurses, patients, and physicians. American Journal of Nursing, 109, 21-25.

Christianson, Marlys K. (2018). Mapping the terrain. Organizational Research Methods, 21, 261287.

Christianson, Marlys K. (2019). More and less effective updating: The role of trajectory management in making sense again. Administrative Science Quarterly, 64, 45-86.

Cnossen, Boukje \& Bencherki, Nicolas (2019). The role of space in the emergence and endurance of organizing: How independent workers and material assemblages constitute organizations. Human Relations, 72, 1057-1080.

Cornelissen, Joep P., Mantere, Saku \& Vaara, Eero (2014). The contraction of meaning: The combined effect of communication, emotions, and materiality on sensemaking in the Stockwell Shooting. Journal of Management Studies, 51, 699-736.

Danner-Schröder, Anja \& Geiger, Daniel (2016). Unravelling the motor of patterning work: Toward an understanding of the microlevel dynamics of standardization and flexibility. Organization Science, 27, 633-658.

de Rond, Mark, Holeman, Isaac \& Howard-Grenville, Jennifer (2019). Sensemaking from the body: An enactive ethnography of rowing the Amazon. Academy of Management Journal, 62, 1961-1988.

Dunbar, Roger L. M. \& Garud, Raghu (2009). Distributed knowledge and indeterminate meaning: The case of the Columbia shuttle flight. Organization Studies, 30, 397-421.

Dwyer, Graham, Hardy, Cynthia \& Maguire, Steve (2021). Post-inquiry sensemaking: The case of the 'Black Saturday' bushfires. Organization Studies, 42, 637-661.

Eisenhardt, Kathleen M. (1989). Building theories from case study research. Academy of Management Review, 14, 532-560. 
Faraj, Samer \& Xiao, Yan (2006). Coordination in fast-response organizations. Management Science, 52, 1155-1169.

Gary, Michael Shayne \& Wood, Robert E. (2011). Mental models, decision rules, and performance heterogeneity. Strategic Management Journal, 32, 569-594.

Giovannoni, Elena \& Quattrone, Paolo (2018). The materiality of absence: Organizing and the case of the incomplete cathedral. Organization Studies, 39, 849-871.

Gonsalves, Leroy (2020). From face time to flex time: The role of physical space in worker temporal flexibility. Administrative Science Quarterly, 65, 1058-1091.

Gylfe, Philip, Franck, Henrika, LeBaron, Curtis \& Mantere, Saku (2016). Video methods in strategy research: Focusing on embodied cognition. Strategic Management Journal, 37, 133-148.

Halford, Susan \& Leonard, Pauline (2006). Place, space and time: Contextualizing workplace subjectivities. Organization Studies, 27, 657-676.

Harris, Stanley G. (1994), Organizational culture and individual sensemaking: A schema-based perspective'. Organization Science, 5, 309-321.

Helmreich, Robert L. \& Merritt, Ashleigh C. (2017). Safety and error management: The role of crew resource management in ayiation resource management. Proceedings of the Fourth Australian Aviation Psychology Symposium, Vol. 1.

Hoffman, Robert R., Crandall, Beth \& Shadbolt, Nigel (1998). Use of the critical decision method to elicit expert knowledge: A case study in the methodology of cognitive task analysis. Human Factors: The Journal of the Human Factors and Ergonomics Society, 40, 254-276.

Hutchins, Edwin (1995). Cognition in the wild. Cambridge, MA: MIT Press.

Hällgren, Markus, Rouleau, Linda \& de Rond, Mark (2018). A matter of life and death: How extreme context research matters for management and organization studies. Academy of Management Annals, 12, 111-153.

Introna, Lucas D. (2019). On the making of sense in sensemaking: Decentred sensemaking in the meshwork of life. Organization Studies, 40, 745-764.

Kornberger, Martin, Leixnering, Stephan \& Meyer, Renate E. (2019). The logic of tact. How decisions happen in situations of crisis. Organization Studies, 40, 239-266.

LeBaron, Curtis, Jarzabkowski, Paula, Pratt, Michael G. \& Fetzer, Greg (2018). An introduction to video methods in organizational research. Organizational Research Methods, 21, 239-260. 
Lee, Sunkee (2019). Learning-by-moving: Can reconfiguring spatial proximity between organizational members promote individual-level exploration?. Organization Science, 30, 467488.

Liu, Feng \& Maitlis, Sally (2014). Emotional dynamics and strategizing processes: A study of strategic conversations in top team meetings. Journal of Management Studies, 51, 202-234.

Maitlis, Sally (2005). The social process of organizational sensemaking. Academy of Management Journal, 49, 21-49.

Maitlis, Sally \& Christianson, Marlys (2014). Sensemaking in organizations: Taking stock and moving forward. The Academy of Management Annals, 8, 57-125.

Mantere, Saku \& Ketokivi, Mikko (2013). Reasoning in organization science. Academy of Management Review, 38, 70-89.

Mengis, Jeanne, Nicolini, Davide \& Gorli, Mara (2018). The video production of space. Organizational Research Methods, 21, 288-315.

Møller, Anders (2014). Guide to coordination of major SAR incidents at sea (Mass Rescue Operations). Frederikshavn: Naval Warfare Centre Denmark.

O'Neil, Patrick D. \& Kriz, Kenneth A (2013). Do high-reliability systems have lower error rates? Evidence from commercial aircraft accidents. Public Administration Review, 73, 601-612.

Oliver, Nick, Calvard, Thomas \& Potočnik, Kristina (2017). Cognition, technology, and organizationallLimits: Lessons from the Air France 447 disaster. Organization Science, 28, 729 743.

Ratner, Helene (2020). Topologies of organization: Space in continuous deformation. Organization Studies, 41, 1513-1530.

Salas, Eduardo, Wilson, Katherine A., Burke, C. Shawn \& Wightman, Dennis C. (2006). Does crew resource management training work? An update, and extension, and some critical needs. Human Factors, 48, 392-412.

Sandberg, Jörgen \& Tsoukas, Haridimos (2015). Making sense of the sensemaking perspective: Its constituents, limitations, and opportunities for further development. Journal of Organizational Behavior, 36, S6-S32.

Sandberg, Jörgen \& Tsoukas, Haridimos (2020). Sensemaking reconsidered: Towards a broader understanding through phenomenology. Organization Theory, 1, 1-34.

Schakel, Jan-Kees, van Fenema, Paul C. \& Faraj, Samer (2016). Shots fired! Switching between practices in police work. Organization Science, 27, 391-410. 
Schildt, Henri, Mantere, Saku \& Cornelissen, Joep (2020). Power in sensemaking processes. Organization Studies, 41, 241-265.

Sergeeva, Anastasia V., Faraj, Samer \& Huysman, Marleen (2020). Losing touch: An embodiment perspective on coordination in robotic surgery. Organization Science, 31, 1248-1271.

Sivunen, Anu \& Putnam, Linda L. (2019). The dialectics of spatial performances: The interplay of tensions in activity-based organizing. Human Relations, 73, 1129-1156.

Sonenshein, Scott (2016). How corporations overcome issue illegitimacy and issue equivocality to address social welfare: The role of the social change agent. Academy of Management Review, 41, $349-366$.

Stachowski, Alicia A., Kaplan, Seth A. \& Waller, Mary J. (2009). The benefits of flexible team interaction during crises. The Journal of Applied Psychology, 94, 1536-1543.

Steigenberger, Norbert (2016). Organizing for the big one: A review of case studies and a research agenda for multi-agency disaster response. Journal of Contingencies and Crisis Management, 24, $60-72$.

Stephenson, Kathleen A., Kuismin, Ari, Putnam, Linda L. \& Sivunen, Anu (2020). Process studies of organizational space. Academy of Management Annals, 14, 797-827.

Taylor, Scott \& Spicer, André (2007). Time for space: A narrative review of research on organizational spaces. International Journal of Management Reviews, 9, 325-346.

Weick, Karl E. (1988). Enacted sensemaking in crisis situations. Journal of Management Studies, 25, 305-317.

Weick, Karl E. (1993). The collapse of sensemaking in organizations: The Mann Gulch disaster. Administrative Science Quarterly, 38, 628-652.

Weick, Karl E. (2010). Reflections on enacted sensemaking in the Bhopal disaster. Journal of Management Studies, 47, 537-550.

Weick, Karl E. \& Roberts, Karlene H. (1993). Collective mind in organizations: Heedfull interelating on flight decks. Administrative Science Quarterly, 38, 357-381.

Weick, Karl E., Sutcliffe, Kathleen M. \& Obstfeld, David (2005). Organizing and the process of sensemaking. Organization Science, 16, 409-421.

Weinfurtner, Tania \& Seidl, David (2019). Towards a spatial perspective: An integrative review of research on organisational space. Scandinavian Journal of Management, 35, 1-30.

Wiener, Earl L., Kanki, Barbara G. \& Helmreich, Robert L. (1993). Cockpit resource management. San Diego, CA: Academic Press. 


\section{Author Bio}

Norbert Steigenberger is an associate professor at Jönköping International Business School. He received his PdD from Chemnitz Technical University in 2011 and held a researcher position at the University of Cologne. He is interested in the organization of novelty and complexity, works at the intersection of organization theory and entrepreneurship, and has a special interest in fastresponse organizations and extreme contexts.

Thomas Lübcke is Head of Research \& Development at the German Maritime Search and Rescue Service (DGzRS). After his studies in organizational science (M.A. sociology/adult education) at University of Rostock in 2006, he conducted research on high-performance teams in different domains. He joined DGzRS in 2012, where he primarily works on topics related to the management of major maritime incidents. For this, he mainly uses qualitative approaches, for example to investigate decision-making processes or sensemaking in the context of search and rescue missions. Further work concerns the development of simulations as well as the development and integration of mission support systems, such as drones and AI-based assistance systems for rescue operations. 